\title{
Lung cancer among women - identifying risk factors
}

\author{
Address for correspondence: \\ Prof. dr hab. n. med. \\ Joanna Domagała-Kulawik \\ Department of Internal Medicine, \\ Pulmonary Diseases and Allergy, \\ Medical University of Warsaw \\ ul. Banacha 1a \\ 02-097 Warsaw, Poland \\ e-mail: jdomagala@wum.edu.pl
}

Oncology in Clinical Practice

2021, Vol. 17, No. 5, 222-228

DOI: $10.5603 / \mathrm{OCP} .2021 .0020$

Copyright (C) 2021 Via Medica

ISSN 2450-1654

e-ISSN 2450-6478

\begin{abstract}
The number of lung cancer cases estimates globally 2 million according to $\mathrm{WHO}$, which represents approximately $11.6 \%$ of all cancers. The problem of lung diseases among women and women's lung cancer is relatively not often discussed in the literature. There is evidence that there is a different distribution of histological types between sexes. The prevalence of adenocarcinoma (ADC) among women is observed for many years with an increasing tendency. This review focuses on the lung cancer risk factors such as tobacco smoking, second-hand smoke exposure, genetic and environmental factors, comorbidities and infectious agents. The declining tendency in smoking points to the necessity of focusing on other risk factors. Analysis of them within the context of morbidity and mortality can help to develop more effective screening programs.
\end{abstract}

Key words: lung cancer, women, smoking, adenocarcinoma, risk factors

Oncol Clin Pract 2021; 17, 5: 222-228

\section{Introduction}

The number of lung cases estimates at 2 million according to $\mathrm{WHO}$, which represents approximately $11.6 \%$ of all cancers. Global statistics concerning women show 725 thousand new cases and 576 thousand deaths due to that reason in 2018. The highest female age-standardised rate per 100,000 is observed in Hungary, Denmark, Netherlands (41.4-32.7) [1, 2]. In Poland, 7747 new cases among women were reported in 2017. Unfortunately, the number of deaths per year was higher - 7825 [3]. The 5-year life expectancy of patients with lung cancer is estimated at $13.5 \%$ [4].

Large analysis relating global patterns and temporal trends in incidence and mortality of lung cancer based on data from high-quality cancer registries was conducted by Wong et al. The conclusions revealed increasing trends of incidence among women in 19 countries, one with decreasing incidence, and 18 countries with stable incidence out of 38 countries. There were 16 countries with increasing mortality trends, 6 countries with de- creasing trends and 14 countries with stable trends among women out of 36 countries [5]. The ageing of the female population born after World War II and their high tobacco consumption, improvement of health care of chronic diseases can partly explain that appearance.

There is evidence that there is a different distribution of histological types between sex. The prevalence of adenocarcinoma (ADC) among women is observed for many years with an increasing tendency. In one large study, the data concerning the epidemiology of ADC are presented based on cancer registry (Cancer Incidence in Five Countries, CI5) in the years 1998-2002 [6]. An increase of age-adjusted incidence of ADC among women was observed in all countries; in some countries, it was as high as twofold. The mean proportion of ADC of all lung cancer histological subtypes was higher among women than among men ( $45 v s .34 \%$, respectively).

The influence of sex is also the subject of study in lung cancer treatment. The goal of the Swedish nationwide cohort was an analysis of the differences

\section{Received: 08.02.2021 Accepted: 04.05.2021 Early publication date: 10.06.2021}

This article is available in open access under Creative Common Attribution-Non-Commercial-No Derivatives 4.0 International (CC BY-NC-ND 4.0) license, allowing to download articles and share them with others as long as they credit the authors and the publisher, but without permission to change them in any way or use them commercially. 
in prognosis after pulmonary resection for lung cancer between men and women. The results show that women who underwent pulmonary resections for lung cancer had a significantly better prognosis than men [7]. The progress of new systemic therapies: molecular guided and immune-based therapy contributed to the improvement of survival in NSCLC. The benefit seems to be better among women than in men: 2-years survival improved from 26 to $35 \%$ in men and from 35 to $44 \%$ among women in the US from 2001 to 2016 [8].

The problem of lung diseases among women and women's lung cancer is relatively not often discussed in the literature and has not been embedded in clinical practice. Current aspects of lung cancer among women including the latest topics for research and the evidence on the specificity of female lung cancer were summarized in the authors' previous review [9]. This review focuses on the risk factors which are special for this serious disease among women. Some aspects of this problem are well documented, some of them appear in the minds of researchers. The authors believe that this overview will enrich the clinical practice of oncologists.

\section{Tobacco smoking}

There is no doubt that smoking remains the main factor that causes lung cancer [10]. Tar which is formed after removing nicotine and water from cigarette smoke consists of about 3500 different compounds and most of them are carcinogenic [11].

There is a widespread opinion that lung cancer incidence is higher among smoking men than women and never-smoking women than men. The higher susceptibility by women to tobacco smoke was postulated. Whereas the large epidemiological studies did not confirm this view and only a nonsignificant tendency supporting it was shown $[12,13]$. Even reverse relationships have been found in the large observation in the United States population the age-standardized lung cancer death rates among never-smoking men was $17.1 / 100000$ vs. $14.7 / 100000$ in women [14]. It should be pointed that it concerns one country, and it was race dependent.

Fortunately, the latest global trends estimated by WHO points out that the rates of prevalence of current tobacco use are declining (Fig. 1). The total number of smoking women is predicted to be reduced to $212 \mathrm{mil}$ lion by 2025 [15]. This reduction is observed in all world regions being slowest in European countries. However, cigarette smoke remains a "legally available consumer product which kills people". The increase in the number of tobacco smoke victims is highest in developing

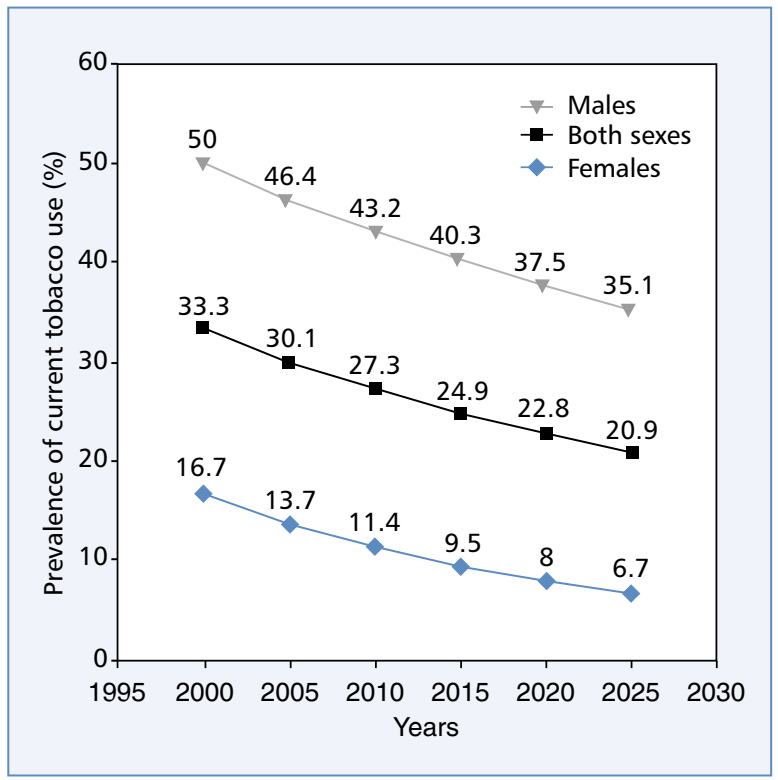

Figure 1. Global trends in the prevalence of tobacco use by sex based on World Health Organization [11]

countries. Cigarette consumption is still very high among women in these countries with the prevalence of young women [15]. Recently, two-thirds of smokers are citizens of 10 countries, among them: Indonesia, Bangladesh, Turkey.

Unfortunately, Poland is a country with high tobacco consumption. Thus, the Polish data is presented. The estimated current tobacco smoking prevalence (age-standardised rate) in Polish females is $21.6 \%$ (vs. $30.3 \%$ in men) and it also shows declining trends over the last eleven years [16]. The most recent Polish representative survey reporting the prevalence of smoking (from 2019) reveals that the highest prevalence of smoking was observed among women aged $30-39$ years. It is noticeable that divorced women smoked more often than married, single or widowed. Women smoked the most in cities between 20,000-500,000 citizens. They choose mainly regular cigarettes and hand-rolled tobacco products. Heated tobacco products and smokeless tobacco use are not popular in Polish women $(2.1 \%$ and $0.6 \%$, respectively) [17].

Considering the influence of e-cigarettes on the lung a few toxicological studies were conducted. The results pay attention to their adverse effects like cytotoxicity, oxidative stress and inflammatory response, reduction of the features of obturation in pulmonary function tests (FEV1/FVC) and a fraction of exhaled nitric oxide (FENO). The authors warn about the lack of studies involving the long-term health impact of these products [18]. It should be highlighted that the carcinogenic effect of classic cigarettes is incomparably higher than these products. 


\section{ETS exposure}

Monitoring decreasing global tendency of smoking habit and taking into consideration diagnosis of lung cancer in never-smokers (10-15\% of all cases) [19] one should focus on finding other risks factors of lung cancer. The problem, which is much more predominant among women than in men is second-hand smoke exposure (environmental tobacco smoke, ETS). In 2004 Oberg and at. conducted analysis of data from 192 countries which estimates that $35 \%$ of non-smoking females were exposed to second-hand smoke what had resulted in death from ischaemic heart disease, lower respiratory infections, asthma, and lung cancer. In total 603,000 deaths were attributable to second-hand smoke and lung cancer was a cause of 21,400 deaths. More deaths from second-hand smoke occurred among women ( $47 \%$, compared to $26 \%$ in men) in this cohort [20]. It gives the reason for concerning the necessity of implementation of careful asking females about second-hand smoke exposure in medical anamneses and considering the participation of them in screening programs.

\section{Genetic risk factors}

Wakelee et al. [12] conducted a review based on the large, population-based cohorts which revealed that age-adjusted incidence rates of lung cancer among never-smokers aged 40 to 79 years ranged from 14.4 to 20.8 among women and 4.8 to 13.7 in men (per 100,000 person-years) what indicate that women are more likely than men to have lung cancer without smoking history and that genetic factors may be responsible for this fact. The primary characteristics of never-smokers compared to tobacco smokers with lung cancer are female sex, ADC histology and East Asian ethnicity [21-23].

The development of molecular pathology leads to precision diagnosis for lung cancer with recognition of molecular alterations which are the basis for targeted therapies [24]. Epidermal growth factor receptor (EGFR) and KRAS activating mutations are the most common in ADC. The proportion of molecular alterations incidence depends on smoking history, ethnicity and sex [25]. EGFR mutation occurs in the Asian population more often than in the Western population $(47.9 \%$ vs. $19.2 \%$ ) [26], and more often in non-smokers (43\% vs. $11 \%$ in smokers) [27]. EGFR mutation is observed among Asian women even up to $60 \%$ [28]. In general, the most frequently observed mutated gene is $\mathrm{p} 53$. The prevalence of KRAS mutations is estimated at 15-30\% [29]. Different genetic alterations are depending on the histopathologic type of lung cancer. The most frequently mutated genes in ADC are KRAS, EGFR, MLL3, and $S T K 11$; whereas in squamous cell carcinomas, there are PI3KCA, SOX2, CDK2, P63, FGFR1 and in small cell lung cancer: RB1, MLL2, SMO, and PI3KCA. Anticancer drug development has been made possible by anti-EGFR and anti-ALK/ROS1 therapeutics (tyrosine kinase inhibitors, TKIs) which play a critical role in the treatment of a selected group of patients [30, 31]. The greater benefit of TKIs is observed among women than in men.

When investigating the subject of genetic reasons of lung cancer, one cannot ignore genome-wide association studies that showed that variations at $5 \mathrm{p} 15.33,6 \mathrm{p} 21.33$, and $15 q 25.1,9 p 21.3$ can influence the risk of cancer in European populations [11, 32].

In a study from 2020, Xuemei Ji et al. [33] suggest KIAA0930 as a novel candidate gene for lung cancer risk (located at 22q13.31).

\section{Other individual factors}

A systematic review was performed to check if family history of lung cancer influences lung cancer risk. The results based on twenty-eight publications revealed that lung cancer risk of the probands' first-degree relatives was 1.88 times higher than that of their controls [34]. However, a family history of lung cancer was not associated with the female sex in the EGFR mutated cohort in the Gaughan et al. study [35].

Recently an interesting report showed two cases of paediatric lung cancers that probably developed through mother-to-infant transmission of cervical carcinoma. The authors assume that tumours arose from mother-to-infant vaginal transmission through aspiration of tumour-contaminated vaginal fluids during birth. They observed a similarity of the gene profiles of the tumour samples from the mothers and children [36].

The role of oestrogens in lung cancer development and progression is well established $[37,38]$ and previously described by the authors in details [9]. Briefly: oestrogen receptors are identified in lung tissue, cancer tissue and the cells which form tumour environment [39]. Thus, lung cancer development is modified by oestrogens from outside as well as produced locally. Aromatase (ARO) extensively expressed in NSCLC contributes to local oestrogen production. All the above data support hormonal influence on lung cancer among women with some therapeutic implications [40]. Female sex could be a factor considered as that, which influence lung carcinogenesis.

\section{Environmental factors}

The harmfulness of the environment also applies to lung cancer. An important risk factor for lung cancer among women is using solid fuels (coal, biomass, 
and mixed fuels) for in-home cooking or heating. It is noticed mainly in developing countries. A meta-analysis that included studies from Asia, the USA, South America and Europe estimates that the risk of lung cancer among users of solid fuels is $70 \%$ higher than non-users [41].

Air pollution and precisely exposure to particulate matter (PM) in outdoor air pollution with aerodynamic diameter $\leq 2.5 \mu \mathrm{m}$ or fine particles $\left(\mathrm{PM}_{2.5}\right)$ and particles $\leq 10 \mu \mathrm{m}$ or inhalable particles $\left(\mathrm{PM}_{10}\right)$ has an association with the risk of lung cancer [42, 43]. World Health Organization declares diesel engine exhaust as a carcinogen based on evidence of a link with lung cancer $[44,45]$. What is more, scientists consider gaseous pollutants, such as sulphur dioxide $\left(\mathrm{SO}_{2}\right)$, ozone $\left(\mathrm{O}_{3}\right)$, carbon monoxide $(\mathrm{CO})$, and nitrogen dioxide $\left(\mathrm{NO}_{2}\right)$ as potential risk factor. However, results in that topic from previous studies seem to be inconsistent [46, 47]. Occupational carcinogens are well known for years and, what is interesting, a recently published systematic review confirms the increasing role of these risk factors [48]. According to the Global Health Data Exchange, the following agents relate to the death of cancer: arsenic, asbestos, benzene, beryllium, cadmium, chromium, diesel engine exhaust, formaldehyde, nickel, polycyclic aromatic hydrocarbons, silica, sulfuric acid, and trichloroethylene. Most of them relate to lung cancer and the risk for death after exposure to occupational agents increases in both sexes. One of the serious carcinogens is naturally occurring radon, which is considered as a second lung cancer risk factor after smoking. The large analysis of the studies conducted in never-smokers confirmed the relationship between residual radon and lung cancer, which was higher in never than in ever smokers and among man than women [49]. However, the synergistic effect of radon with smoking was pointed in this review leading to the conclusion, that, for both sexes, people living in the radon-prone area $\left(>100 \mathrm{~Bq} / \mathrm{m}^{3}\right)$ should be considered as a high-risk group.

Knowing a passion for dieting among women it is worth to also approach some information about it. In an updated comprehensive literature review based on 58 articles, Fakhri et al. summarized information about diet and its potential influence on lung cancer. A higher risk of lung cancer could be linked to red meat, processed meat, and foods high in total or saturated fats [50]. Some observations present the protective effect on lung parenchyma of some items in the diets like fruits, vegetables, fish, nuts, soy, B vitamins, vitamin D, vitamin E, vitamin C, and zinc. However, US Preventive Services Task Force (USPSTF) concluded that there is still insufficient evidence to recommend any vitamins, minerals, and multivitamin supplementation for lung cancer prevention $[25,51]$.

\section{Comorbidities}

The well-known factors for lung cancer are also chronic pulmonary diseases like chronic obstructive pulmonary disease (COPD) and fibrotic lung diseases. The women who reported COPD were 1.64 times more likely to develop lung cancer than those who reported no history of COPD in a recent analysis, after adjusting for smoking status and intensity, ethnicity, education, BMI and income. The other results show that the associations between COPD and lung cancer were similar across subtypes after adjusting for smoking status and intensity [52]. Numerous clinical problems may occur due to the similarity of the clinical picture of lung cancer and COPD and because of that sometimes a proper diagnosis and appropriate treatment are implemented with delay [53]. Women seem to have a different clinico-radiological phenotype of COPD than men [54]. There is evidence that women produce less sputum than men despite this, they are more likely to have a chronic bronchitic phenotype [55]. However, the results of the study conducted by Kiri et al. [56] showed that COPD increased 3-year mortality in patients with NSCLC regardless of patient age or sex (higher mortality rates was observed above all in patients aged $>65$ years). On the other hand in another study, no significant differences in overall survival between COPD and non-COPD patients with lung cancer have been noticed [57].

The association between lung cancer and interstitial lung disease (ILD) can be partly explained by the history of smoking and physiopathology of fibrogenesis and cancerogenesis. The relative risk of lung cancer is estimated to be 3.5- to 7.3-times higher in patients with ILD and lung cancer is diagnosed among them at 10-20\% [58]. The association between ILD and lung cancer among women compering to men need more detailed investigation.

\section{Infectious agents}

The role of inflammation in favouring carcinogenesis is well known and the pathomechanisms of immune response in lung cancer are widely investigated in the last years [24]. However, it is difficult to present the differences between sex in these processes. Only the results of immunotherapy were found to be better or worse among women depending on the study [9]. Thus, one aspect of inflammation connected with infections is presented. Considering infectious risk factors of lung cancer in females one cannot ignore the influence of viral infections in particular human papillomavirus (HPV) and HIV. In various studies, the presence of oncogenic HPV DNA (type 16 and 18) in lung tumour tissues was 
identified [59]. In an international pooled analysis HPV was found to be present more likely in lung cancer tissue than normal lung [60]. The meta-analysis conducted by Zhai K et al. indicated that lung with HPV infection has a strong association with lung cancer. Principally, HPV 16 and 18 infections significantly increase the risk of lung squamous cell carcinoma [61]. This may lead to reflect on a special screening for lung cancer in women with HPV infection.

Non-AIDS defining cancers (NADC) are an important cause of morbidity and mortality in HIV-positive individuals. NADCs of the lung are mostly comprised of non-small cell lung cancer (NSCLC), followed by small cell lung cancer (SCLC). The incidence of lung cancer in HIV-infected persons estimates 80-170 cases per 100,000 person-years $[62,63]$. The hypothesis for association between lung cancer and HIV infection refers to chronic pulmonary inflammation connected with infections contributes to carcinogenesis [64]. The role of HIV infection alone was also investigated. The results are inconclusive. Sigel et al. [56] indicated that HIV was an independent risk factor for lung cancer after controlling for potential confounders including smoking. On the other hand, Hessol et al. [65] showed that HIV infection alone was not an independent risk factor for lung cancer but that the amount of cigarette smoking and prior AIDS pneumonia were major factors for the development of lung cancer among HIV-infected patients.

COVID-19 infection involving currently according to WHO more than 100 million confirmed cases and causing more than 2 million death globally is a new factor which causes the acute respiratory disorder. There are some clinical findings in COVID-19 patients which are also reported to be high-risk findings associated with lung cancer development. However, the speculations about the impact of COVID-19 on lung cancer risk seem to be premature

The ground-glass opacity (GGO) (widespread among COVID-19 patients) is a frequent radiological finding in a patient with lung cancer $[66,67]$. The strategy for GGO in lung cancer screening is the subject of international discussions and regulations. There may be a need for follow up in the patients with persistent GGO after SARCov-2 infection for early detection of the pre-neoplastic lesions [68]. Another common aspect of COVID-19 infection and lung cancer are disturbances in the immune system. In the blood of COVID-19 infected patients the concentration of IL-6, IFN $\gamma$, MCP1, and IP10 were found to be elevated during COVID-19 [69, 70]. These cytokines are involved in invasion, metastasis, and epithelial-mesenchymal transition in lung cancer. An interesting current result of meta-analysis including 3,111,714 globally reported cases of confirmed COVID-19 patients showed that there is no difference

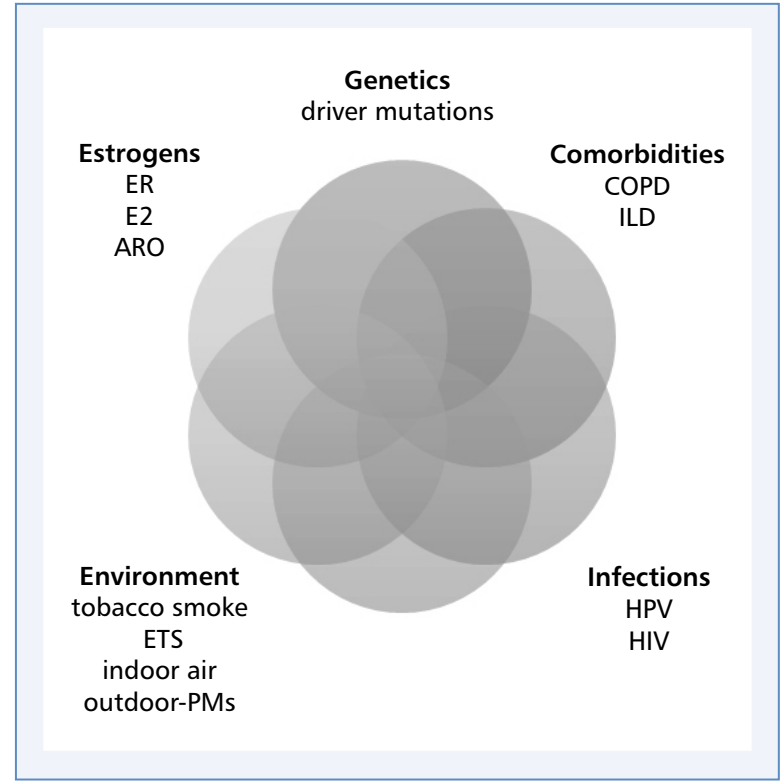

Figure 2. Possible and documented risk factors for lung cancer among women; ARO - aromatase; ER - oestrogen receptor; E2 - 17- $\beta$-oestradiol; ETS - environmental tobacco smoke; COPD - chronic obstructive lung disease; HPV - human papillomavirus; HIV - human immunodeficiency virus; ILD - interstitial lung diseases; PMs — particular matters

in the proportion of infection between males and females, however, men have almost three times the odds of requiring intensive treatment unit admission and higher odds of death compared to women. These results have highlighted the importance of considering sex as a variable in fundamental and clinical research and can help in the clinical management of COVID-19 [71]. The new global problem which is COVID-19 needs further investigations.

\section{Conclusion}

Lung cancer, which has been associated with the male sex for years, has become a serious problem among women. The declining tendency in smoking induces focusing on other risk factors. An analysis of current risk factors within the context of morbidity and mortality can help to develop effective screening programs. The most important risk factors which need intensive investigations for lung cancer in women are summarized in Figure 2.

\section{Conflict of interest}

The authors have declared no conflicts of interest. 


\section{References}

1. World Cancer Research Fund, Lung cancer statistics. https://www.wcrf org/dietandcancer/cancer-trends/lung-cancer-statistics.

2. WHO, International Agency for Research on Cancer (Globocan 2018) https://gco.iarc.fr/today/data/factsheets/cancers/15-Lung-fact-sheet. pdf.

3. Ditkowska J, Wojciechowska U, Olasek P. Cancer in Poland in 2017. Krajowy Rejestr Nowotworów 2017.

4. Krzakowski M, Jassem J, Antczak A, et al. Cancer of the lung pleura and mediastinum. Oncol Clin Pract. 2019; 15(1): 20-50, doi: 10.5603/OCP.2018.0056.

5. Wong MCS, Lao XQ, Ho KF, et al. Incidence and mortality of lung cancer: global trends and association with socioeconomic status. Sc Rep. 2017; 7(1): 14300, doi: 10.1038/s41598-017-14513-7, indexed in Pubmed: 29085026.

6. Lortet-Tieulent J, Soerjomataram I, Ferlay J, et al. International trends in lung cancer incidence by histological subtype: Adenocarcinoma stabilizing in men but still increasing in women. Lung Cancer. 2014; 84(1): 13-22, doi: 10.1016/j.lungcan.2014.01.009.

7. Sachs E, Sartipy U, Jackson V. Sex and Survival After Surgery for Lung Cancer: A Swedish Nationwide Cohort. Chest. 2021; 159(5): 2029-2039, doi: 10.1016/j.chest.2020.11.010, indexed in Pubmed: 33217414

8. Howlader N, Forjaz G, Mooradian MJ, et al. The Effect of Advances in Lung-Cancer Treatment on Population Mortality. N Engl J Med. 2020; 383(7): 640-649, doi: 10.1056/NEJMoa1916623, indexed in Pubmed: 32786189.

9. Domagala-Kulawik J, Trojnar A. Lung cancer in women in 21th century. J Thorac Dis. 2020; 12(8): 4398-4410, doi: 10.21037/jtd-20-287, indexed in Pubmed: 32944353.

10. Doll R, Hill AB. Smoking and carcinoma of the lung. Preliminary report. 1950. Bull World Health Organ. 1999; 77(1): 84-93, indexed in Pubmed: 10063665.

11. Akhtar N, Bansal JG. Risk factors of Lung Cancer in nonsmoker. Curr Probl Cancer. 2017; 41(5): 328-339, doi: 10.1016/j.currproblcancer.2017.07.002, indexed in Pubmed: 28823540.

12. Wakelee HA, Chang ET, Gomez SL, et al. Lung cancer incidence in never smokers. J Clin Oncol. 2007; 25(5): 472-478, doi: 10.1200/JCO.2006.07.2983, indexed in Pubmed: 17290054.

13. O'Keeffe LM, Taylor G, Huxley RR, et al. Smoking as a risk factor for lung cancer in women and men: a systematic review and meta-analysis. BMJ Open. 2018; 8(10): e021611, doi: 10.1136/bmjopen-2018-021611, indexed in Pubmed: 30287668.

14. Thun MJ, Henley SJ, Burns D, et al. Lung cancer death rates in lifelong nonsmokers. J Natl Cancer Inst. 2006; 98(10): 691-699, doi: 10.1093/inci/dij187, indexed in Pubmed: 16705123.

15. WHO global report on trends in prevalence of tobacco use 20002025, Third edition. https://www.who.int/publications/i/item/whoglobal-report-on-trends-in-prevalence-of-tobacco-use-2000-2025third-edition.

16. WHO The Global Health Observatory, Age-standardized estimates of current tobacco use, tobacco smoking and cigarette smoking. https:// www.who.int/data/gho/data/indicators/indicator-details/GHO/ghotobacco-control-monitor-current-tobaccouse-tobaccosmoking-cig arrettesmoking-agestd-tobagestdcurr.

17. Pinkas J, Kaleta D, Zgliczyński WS, et al. The Prevalence of Tobacco and E-Cigarette Use in Poland: A 2019 Nationwide Cross-Sectional Survey. Int J Environ Res Public Health. 2019; 16(23), doi: 10.3390/ijerph16234820, indexed in Pubmed: 31801221.

18. Kaisar MA, Prasad S, Liles T, et al. A decade of e-cigarettes: Limited research \& unresolved safety concerns. Toxicology. 2016; 365: 67-75, doi: 10.1016/i.tox.2016.07.020, indexed in Pubmed: 27477296.

19. Samet JM, Avila-Tang E, Boffetta $P$, et al. Lung cancer in never smokers: clinical epidemiology and environmental risk factors. Clin Cancer Res. 2009; 15(18): 5626-5645, doi: 10.1158/1078-0432. CCR-09-0376, indexed in Pubmed: 19755391.

20. Oberg M, Jaakkola MS, Woodward A, et al. Worldwide burden of disease from exposure to second-hand smoke: a retrospective anaIysis of data from 192 countries. Lancet. 2011; 377(9760): 139-146, doi: 10.1016/S0140-6736(10)61388-8, indexed in Pubmed: 21112082

21. Toh CK, Gao F, Lim WT, et al. Never-smokers with lung cancer: epidemiologic evidence of a distinct disease entity. J Clin Oncol. 2006; 24(15): 2245-2251, doi: 10.1200/JCO.2005.04.8033, indexed in Pubmed: 16710022.

22. Subramanian J, Velcheti V, Gao F, et al. Presentation and stage-specific outcomes of lifelong never-smokers with non-small cell lung cancer (NSCLC). J Thorac Oncol. 2007; 2(9): 827-830, doi: 10.1097/JTO .0b013e318145af79, indexed in Pubmed: 17805060.
23. Nordquist LT, Simon GR, Cantor A, et al. Improved survival in never-smokers vs current smokers with primary adenocarcinoma of the lung. Chest. 2004; 126(2): 347-351, doi: 10.1378/chest.126.2.347, indexed in Pubmed: 15302716.

24. Domagala-Kulawik J. New Frontiers for Molecular Pathology. Front Med (Lausanne). 2019; 6: 284, doi: 10.3389/fmed.2019.00284, indexed in Pubmed: 31867335 .

25. Barta JA, Powell CA, Wisnivesky JP. Global Epidemiology of Lung Cancer. Ann Glob Health. 2019; 85(1), doi: 10.5334/aogh.2419, indexed in Pubmed: 30741509.

26. Dearden S, Stevens J, Wu YL et al. Mutation incidence and coincidence in non small-cell lung cancer: meta-analyses by ethnicity and histology (mutMap). Ann Oncol. 2013; 24(9): 2371-2376, doi: 10.1093/annonc/mdt205, indexed in Pubmed: 23723294.

27. Dogan S, Shen R, Ang DC, et al. Molecular epidemiology of EGFR and KRAS mutations in 3,026 lung adenocarcinomas: higher susceptibility of women to smoking-related KRAS-mutant cancers. Clin Cancer Res. 2012; 18(22): 6169-6177, doi: 10.1158/1078-0432.CCR-11-3265, indexed in Pubmed: 23014527.

28. Shi Y, Au JSK, Thongprasert S, et al. A prospective, molecular epidemiology study of EGFR mutations in Asian patients with advanced non-small-cell lung cancer of adenocarcinoma histology (PIONEER). J Thorac Oncol. 2014; 9(2): 154-162, doi: 10.1097/JTO.0000000000000033, indexed in Pubmed: 24419411.

29. Levy MA, Lovly CM, Pao W. Translating genomic information into clinical medicine: lung cancer as a paradigm. Genome Res. 2012; 22(11): 2101-2108, doi: 10.1101/gr.131128.111, indexed in Pubmed: 23019146.

30. Fang B, Mehran RJ, Heymach JV, et al. Predictive biomarkers in precision medicine and drug development against lung cancer. Chin J Cancer. 2015; 34(7): 295-309, doi: 10.1186/s40880-015-0028-4, indexed in Pubmed: 26134262

31. de Sousa VM, Carvalho L. Heterogeneity in Lung Cancer. Pathobiology. 2018; 85(1-2): 96-107, doi: 10.1159/000487440, indexed in Pubmed: 29635240 .

32. Timofeeva MN, Hung RJ, Rafnar T, et al. Transdisciplinary Research in Cancer of the Lung (TRICL) Research Team. Influence of common genetic variation on lung cancer risk: meta-analysis of 14900 cases and 29485 controls. Hum Mol Genet. 2012; 21(22): 4980-4995, doi: 10.1093/hmg/dds334, indexed in Pubmed: 22899653.

33. Ji X, Mukherjee S, Landi MT, et al. Protein-altering germline mutations implicate novel genes related to lung cancer development. Nat Commun. 2020; 11(1): 2220, doi: 10.1038/s41467-020-15905-6, indexed in Pubmed: 32393777

34. Gu J, Hua F, Zhong D, et al. [Systematic review of the relationship between family history of lung cancer and lung cancer risk]. Zhongguo Fei Ai Za Zhi. 2010; 13(3): 224-229, doi: 10.3779/j.issn.10093419.2010.03.07, indexed in Pubmed: 20673520.

35. Gaughan EM, Cryer SK, Yeap BY, et al. Family history of lung cancer in never smokers with non-small-cell lung cancer and its association with tumors harboring EGFR mutations. Lung Cancer. 2013; 79(3) 193-197, doi: 10.1016/j.lungcan.2012.12.002, indexed in Pubmed: 23273562

36. Arakawa A, Ichikawa H, Kubo T, et al. Vaginal Transmission of Cancer from Mothers with Cervical Cancer to Infants. N Engl J Med. 2021; 384(1): 42-50, doi: 10.1056/NEJMoa2030391, indexed in Pubmed: 33406329

37. Rodriguez-Lara V, Hernandez-Martinez JM, Arrieta O. Influence of estrogen in non-small cell lung cancer and its clinical implications. J Thorac Dis. 2018; 10(1): 482-497, doi: 10.21037/jtd.2017.12.61, indexed in Pubmed: 29600083

38. Hsu LH, Chu NM, Kao SH. Estrogen, Estrogen Receptor and Lung Cancer. Int J Mol Sci. 2017; 18(8): 1713, doi: 10.3390/ijms18081713.

39. Smida T, Bruno TC, Stabile LP. Influence of Estrogen on the NSCLC Microenvironment: A Comprehensive Picture and Clinical Implications. Front Oncol. 2020; 10: 137, doi: 10.3389/fonc.2020.00137, indexed in Pubmed: 32133288.

40. Almotlak AA, Farooqui M, Siegfried JM. Inhibiting Pathways Predicted From a Steroid Hormone Gene Signature Yields Synergistic Antitumor Effects in NSCLC. J Thorac Oncol. 2020; 15(1): 62-79, doi: 10.1016/j. jtho.2019.09.195, indexed in Pubmed: 31606604

41. Kurmi OmP, Arya PH, Lam KBH, et al. Lung cancer risk and solid fuel smoke exposure: a systematic review and meta-analysis. Eur Respir J. 2012; 40(5): 1228-1237, doi: 10.1183/09031936.00099511, indexed in Pubmed: 22653775

42. Hamra GB, Guha N, Cohen A, et al. Outdoor particulate matter exposure and lung cancer: a systematic review and meta-analysis. Environ Health Perspect. 2014; 122(9): 906-911, doi: 10.1289/ehp/1408092, indexed in Pubmed: 24911630 
43. Schraufnagel DE, Balmes JR, Cowl CT, et al. Air Pollution and Noncommunicable Diseases: A Review by the Forum of International Respiratory Societies' Environmental Committee, Part 2: Air Pollution and Organ Systems. Chest. 2019; 155(2): 417-426, doi: 10.1016/j. chest.2018.10.041, indexed in Pubmed: 30419237.

44. Silverman DT. Diesel exhaust causes lung cancer: now what? Occup Environ Med. 2017; 74(4): 233-234, doi: 10.1136/oemed-2016-104197, indexed in Pubmed: 28069968.

45. Benbrahim-Tallaa L, Baan R, Grosse Y, et al. Carcinogenicity of diesel-engine and gasoline-engine exhausts and some nitroarenes. Lance Oncol 2012; 13(7): 663-664, doi: 10.1016/s1470-2045(12)70280-2.

46. Katsouyanni K. Ambient air pollution and health. Br Med Bull. 2003; 68 143-156, doi: 10.1093/bmb/ldg028, indexed in Pubmed: 14757714.

47. Xing DF, Xu CD, Liao XY, et al. Spatial association between outdoo air pollution and lung cancer incidence in China. BMC Public Health 2019; 19(1): 1377, doi: 10.1186/s12889-019-7740-y, indexed in Pubmed: 31655581

48. Li Na, Zhai Z, Zheng Yi, et al. Association of 13 Occupational Carcinogens in Patients With Cancer, Individually and Collectively, 1990-2017. JAMA Netw Open. 2021; 4(2): e2037530, doi: 10.1001/jamanetworkopen.2020.37530, indexed in Pubmed: 33599775

49. Cheng E, Egger S, Hughes S, et al. Systematic review and meta-analysis of residential radon and lung cancer in never-smokers. European Respiratory Review. 2021; 30(159): 200230, doi 10.1183/16000617.0230-2020.

50. Fakhri G, Al Assaad M, Tfayli A. Association of various dietary habits and risk of lung cancer: an updated comprehensive literature review. Tumori. 2020; 106(6): 445-456, doi: 10.1177/0300891619900675 indexed in Pubmed: 32129158.

51. Fortmann SP, Burda BU, Senger CA, et al. Vitamin and mineral supplements in the primary prevention of cardiovascular disease and cancer: An updated systematic evidence review for the U.S. Preventive Services Task Force. Ann Intern Med. 2013; 159(12): 824-834, doi: 10.7326/0003-4819-159-12-201312170-00729, indexed in Pubmed: 24217421

52. Nagasaka M, Lehman A, Chlebowski R, et al. COPD and lung cancer incidence in the Women's Health Initiative Observational Study: A brief report. Lung Cancer. 2020; 141: 78-81, doi: 10.1016/j.lungcan.2020.01.006, indexed in Pubmed: 31958598.

53. Tyl M, Domagała-Kulawik J. Rak płuca i przewlekła obturacyjna choroba płuc - narastający problem kliniczny [Lung cancer and COPD - growing clinical problem]. Pol Merkur Lekarski. 2017; 43(253): 5-9.

54. Gut-Gobert C, Cavaillès A, Dixmier A, et al. Women and COPD do we need more evidence? Eur Respir Rev. 2019; 28(151) doi: 10.1183/16000617.0055-2018, indexed in Pubmed 30814138

55. Watson L, Vestbo J, Postma DS, et al. Gender differences in the management and experience of Chronic Obstructive Pulmonary Disease. Respir Med. 2004; 98(12): 1207-1213, doi: 10.1016/j.rmed.2004.05.004 indexed in Pubmed: 15588042.

56. Kiri VA, Soriano J, Visick G, et al. Recent trends in lung cance and its association with COPD: an analysis using the UK GP Research Database. Prim Care Respir J. 2010; 19(1): 57-61, doi 10.4104/pcrj.2009.00048, indexed in Pubmed: 19756330
57. Izquierdo JL, Resano P, El Hachem A, et al. Impact of COPD in patients with lung cancer and advanced disease treated with chemotherapy and/or tyrosine kinase inhibitors. Int J Chron Obstruct Pulmon Dis. 2014; 9: 1053-1058, doi: 10.2147/COPD.S68766, indexed in Pubmed: 25336937.

58. Naccache JM, Gibiot Q, Monnet I, et al. Lung cancer and interstitial lung disease: a literature review. J Thorac Dis. 2018; 10(6): 3829-3844, doi: 10.21037/itd.2018.05.75, indexed in Pubmed: 30069384.

59. Yu Y, Yang A, Hu S, et al. Correlation of HPV-16/18 infection of human papillomavirus with lung squamous cell carcinomas in Western China. Oncol Rep. 2009; 21(6): 1627-1632, doi: 10.3892/or 00000397, indexed in Pubmed: 19424646.

60. Ragin C, Obikoya-Malomo M, Kim S, et al. HPV-associated lung cancers: an international pooled analysis. Carcinogenesis. 2014; 35(6): 1267-1275, doi: 10.1093/carcin/bgu038, indexed in Pubmed: 24523449.

61. Zhai K, Ding J, Shi HZ, et al. HPV and lung cancer risk: a meta-analysis. J Clin Virol. 2015; 63: 84-90, doi: 10.1016/j.jcv.2014.09.014, indexed in Pubmed: 25315992.

62. Sigel K, Pitts R, Crothers K. Lung Malignancies in HIV Infection. Semin Respir Crit Care Med. 2016; 37(2): 267-276, doi: 10.1055/s-00361578803, indexed in Pubmed: 26974303.

63. Worm SW, Bower M, Reiss P, et al. D:A:D Study Group. Non-AIDS defining cancers in the $D: A: D$ Study--time trends and predictors of survival: a cohort study. BMC Infect Dis. 2013; 13: 471, doi: 10.1186/1471-233413-471, indexed in Pubmed: 24106926.

64. Shebl FM, Engels EA, Goedert JJ, et al. Pulmonary infections and risk of lung cancer among persons with AIDS. J Acquir Immune Defic Syndr. 2010; 55(3): 375-379, doi: 10.1097/QAl.0b013e3181eef4f7, indexed in Pubmed: 20736841

65. Hessol NA, Martínez-Maza O, Levine AM, et al. Lung cancer incidence and survival among HIV-infected and uninfected women and men. AIDS. 2015; 29(10): 1183-1193, doi: 10.1097/QAD.0000000000000690, indexed in Pubmed: 25888645.

66. Sadhukhan P, Ugurlu MT, Hoque MO. Effect of COVID-19 on Lungs: Focusing on Prospective Malignant Phenotypes. Cancers (Basel). 2020; 12(12), doi: 10.3390/cancers12123822, indexed in Pubmed: 33352869.

67. Migliore M Fornito M, Palazzolo $M$, et al Ground glass opacities management in the lung cancer screening era. Ann Transl Med. 2018; 6(5): 90, doi: 10.21037/atm.2017.07.28, indexed in Pubmed: 29666813.

68. Park CM, Goo JMo, Lee HJu, et al. Nodular ground-glass opacity at thin-section CT: histologic correlation and evaluation of change at follow-up. Radiographics. 2007; 27(2): 391-408, doi: 10.1148/rg.272065061, indexed in Pubmed: 17374860.

69. Tay MZ, Poh CM, Rénia L, et al. The trinity of COVID-19: immunity, inflammation and intervention. Nat Rev Immunol. 2020; 20(6): 363-374, doi: 10.1038/s41577-020-0311-8, indexed in Pubmed: 32346093

70. Wang $\mathrm{L}$, Cao L, Wang H, et al. Cancer-associated fibroblasts enhance metastatic potential of lung cancer cells through IL-6/STAT3 signaling pathway. Oncotarget. 2017; 8(44): 76116-76128, doi: 10.18632/oncotarget.18814, indexed in Pubmed: 29100297.

71. Peckham H, de Gruijter NM, Raine C, et al. Male sex identified by global COVID-19 meta-analysis as a risk factor for death and ITU admission. Nat Commun. 2020; 11(1): 6317, doi: 10.1038/s41467-020-19741-6, indexed in Pubmed: 33298944 